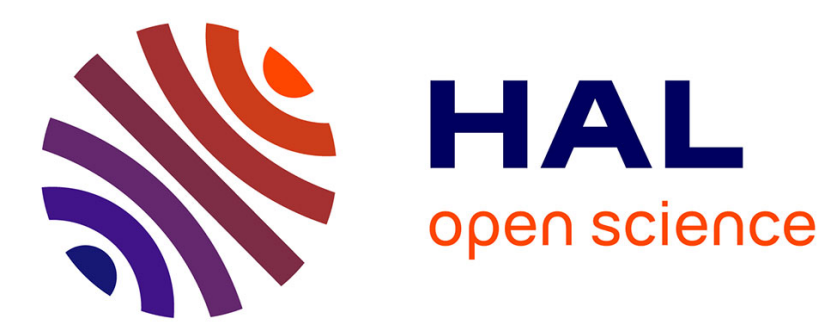

\title{
Assessing the compliance of a product with an eco-label: from standards to constraints
}

\author{
Raymond Houé Ngouna, Bernard Grabot
}

\section{To cite this version:}

Raymond Houé Ngouna, Bernard Grabot. Assessing the compliance of a product with an eco-label: from standards to constraints. International Journal of Production Economics, 2009, vol. 121, pp. 21-38. 10.1016/j.ijpe.2008.03.014 . hal-00965906

\section{HAL Id: hal-00965906 https://hal.science/hal-00965906}

Submitted on 25 Mar 2014

HAL is a multi-disciplinary open access archive for the deposit and dissemination of scientific research documents, whether they are published or not. The documents may come from teaching and research institutions in France or abroad, or from public or private research centers.
L'archive ouverte pluridisciplinaire HAL, est destinée au dépôt et à la diffusion de documents scientifiques de niveau recherche, publiés ou non, émanant des établissements d'enseignement et de recherche français ou étrangers, des laboratoires publics ou privés. 


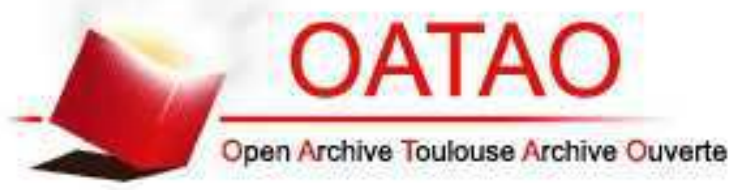

\section{Open Archive Toulouse Archive Ouverte (OATAO)}

OATAO is an open access repository that collects the work of Toulouse researchers and makes it freely available over the web where possible.

This is an author-deposited version published in: http://oatao.univ-toulouse.fr/ Eprints ID: 10927

To link to this article : DOI:10.1016/j.ijpe.2008.03.014

http://dx.doi.org/10.1016/j.ijpe.2008.03.014

\section{To cite this version:}

Houé Ngouna, Raymond and Grabot, Bernard Assessing the compliance of a product with an eco-label: from standards to constraints. (2009) International Journal of Production Economics, vol. 121 ( $\left.\mathrm{n}^{\circ} 1\right)$. pp. 21-38. ISSN 0925-5273 
Assessing the compliance of a product with an eco-label:

from standards to constraints

\title{
Raymond HOUE*, Bernard GRABOT \\ LGP- ENIT (France)
}

\begin{abstract}
The new awareness of the consumers regarding environmental issues should allow companies to gain a competitive advantage by obtaining eco-labels which certify the low impact of a product on the environment. Getting such label requires to analyse a product according to rules expressed in natural language which may be difficult to interpret but also to apply when the product is complex. In order to address this problem, we suggest a method aiming at providing support to the user when checking the compliance of a product with an eco-label. The method is applied on an illustrative example of the literature.
\end{abstract}

Key words: Sustainable development, Eco-label, product model, ORM, constraint propagation. 


\section{Introduction}

Sustainable development is now a major concern in most of the developed countries, resulting in stricter regulations concerning the impact of the products during their manufacturing, use and end of life, including the obligation to define reverse logistics strategies and systems (Kumar and Putnam, 2008, Gou et al., 2008, Hsuan Hong et al., 2008). These regulations can be regarded as new constraints by the designers and manufacturers of developed countries and environmental regulations may be considered as impacting negatively the competitiveness business (Gottberg et al., 2005, Miemczyk, 2008). In spite of this, we do believe that environmental concerns can lead to a competitive advantage against products developed in low cost countries. The recent example of Chinese cars is in our opinion a good example of coercive regulations having for final result to protect a market: in this case, a high level safety standard (the five-stars crash test), considered as very important by the consumers, is not yet met by these low cost cars, preventing their expected immediate commercial success. Similarly, it seems that individual's awareness has now reached the point where more expensive but environment-friendly products can be preferred to cheaper "common" products: legislation, but also customer demand has several times been cited as the most important drivers of eco-design (Argument et al., 1998; McAloone, 1998; van Hemel, 1998). In that case, being compliant with environmental standards becomes a competitive advantage, and not a constraint (Seidel et al., 2006).

Eco-labels, which certify the low impact of a product on the environment, may provide such competitive advantage, since they are only obtained on a voluntary base. Getting such label requires to analyse a product according to rules expressed in natural language which may be difficult to interpret but also to apply when the product is complex. Moreover, these labels are often dedicated to given countries or geographical areas: exporting a product in several countries 
may so require to check its compliance with several labels. As a result, several costly and partially redundant analyses are necessary when different eco-labels are targeted.

In order to address this problem, we suggest in this article a method aiming at providing support to the user when checking the compliance of a product with an eco-label. Several representative eco-labels have firstly been selected and analysed in order to identify the product characteristics on which the rules contained in the eco-labels focus. These characteristics have been gathered in an exhaustive product model composed of several "views". The eco-labels have then been analysed in order to translate the included rules in constraints. Thanks to constraint-based languages (here, CLAIRE), these constraints can be automatically propagated in the product model in order to detect possible inconsistencies by a solver.

The resulting framework can be used in several contexts: support to the designer for choosing the best design solution to comply with an eco-label, assessment of the compliance of an existing product with an eco-label, or comparison of the changes required by different eco-labels on the same product for instance. Coupled with cost analysis techniques, the method can also allow for choosing the cheaper solution allowing to be compliant with a rule.

The context of eco-design and the interests of eco-labels for providing a competitive advantage are investigated in section 2. Examples of studies aiming at facilitating eco-design are given in section 3. The various views of the product model deduced from analysis of representative ecolabels are described in section 4, whereas the translation of rules into constraints is explained in section 5. A limited example of application of the method on a product described in the literature (a CPU) considering the European eco-label is provided in section 6. 


\section{From eco-design to eco-label}

\subsection{General context of environment friendliness and eco-design}

The eco-design concept, also known as Design For Environment - DFE (ISO 14062), aims at providing methods allowing the minimization of the environmental impact of a product during its lifecycle. In the present highly competitive context, designing products which are more respectful for the environment makes sense if the head of the company has strong environmental convictions or more often if the company can get an advantage from this engagement. This involvement can be paid back in terms of image (see for instance (Seidel et al., 2006)) but also in terms of market share: it is now clear that environmental regulations can result in barriers against low cost countries (Gottberg et al., 2006) but may also bring a competitive advantage, in a context of increased consumer awareness on environmental issues (Thogersen, 2002, Teis1, 2002, Mascle and Ping Zhao, 2008).

Design for Environment and its management are based on several interrelated methods (see (Ljunberg, 2007) for a recent review), including aspects such as analysis of the environmental impact of a product (Life Cycle Assessment-LCA, see e.g. Svoboda, 1995), definition of conditions for reuse or recycling (Design For Recycling-DFR, Hundal, 2000; Ishii, 1998) etc.. These methods are themselves based on a patchwork of sub-methods or techniques, like methods aiming at making disassembly (Design For Disassembly - DFD; Campbell and Hans, 2003; Dowie, 1994) or recycling easier (Simon, 1996).

In that complex context, it has often been noticed that consumers do not have competence and time for investigating the environmental impact of products; therefore, those concerned by environmental issues usually prefer to trust a label, given by an external entity, and insuring that the concerned product has a poor impact on the environment (Gallastegui, 2002). 
Such labels belong to three major types (Gallastegui, 2002):

i. Type I labels, also called eco-labels, refer to the environmental quality of a product all along its lifecycle. These labels are the result of third party certification programmes, and are voluntary.

ii. Type II are self-declarations made by the manufacturers, importers or distributors and refer to specific attributes of the products (like "CFC free" products).

iii. Type III labels use pre-set indices and give quantified information on products based on independent verification. They are still rarely found in the environmental field.

Type I labels have until now been the most successful, since labels of Type II do not have the same image of impartiality (they are self-attributed), whereas Type II labels are still rare. Even if producing credible eco-labels is usually considered as a difficult task (Bruce et al., 2007), they are often selected by companies as a mean for giving to their customer a clear and trustable message on their effort regarding sustainability (Seidel et al., 2006). Their efficiency in that purpose is analysed with further details in next section.

\subsection{Interest of eco-labels}

First of all, it is a trivial fact that issues linked to sustainability have only an impact on customers aware of environmental problems (Teisl et al., 2007; Jordan et al., 2003). These customers are until now mainly located in developed countries (Jordan et al., 2003), but even in that case, the level of consciousness - and therefore the potential impact of the eco-labels on the market - varies according the countries. It is usually considered that Nordic countries, Germany and Japan, at the origin of the first eco-labels, still have a real advance on the other developed countries on that concern, but a growing interest on sustainability can be obviously noticed in the US and in the rest of Europe. 
In that context, the positive attitude of the consumers for eco-labelled food products, even if considered as more expensive, is for instance underlined in (Grankvist and Biel, 2007), but the authors consider that this positive attitude is highly correlated with the income of the customers. Generalising from eco-labels in the food industry can lead to erroneous conclusions, since consumers sometimes make a confusion between eco-labels and bio products, considered as more healthy than common ones. Manufactured products would not benefit from the same a priori. Nevertheless, studies related to other domains have shown similar conclusions regarding the positive impact of eco-labels on consumers behaviours, like Teisl et al., 2002) for Dolphin-safe tuna labels, (Lundquist et al., 2006; Teis1, 2007) for cars, (Gottberg et al., 2006) for electrical equipments or (Grankvist et al., 2007) at a more generic level.

If obtaining of an eco-label can open new markets and give a competitive advantage, its absence can in the opposite be a problem: many authors have emphasised that eco-labels can lead to barriers to trade (see a survey in Gallastegui, 2002). This possibility is usually considered as negative in the literature, but can be an interesting point for companies established in environmental-conscious countries.

We shall see in next section what the main eco-labels are and what their typical content is, in order to investigate as a second step their difficulties of use.

\subsection{Typical eco-labels and their content}

It is firstly important to notice that eco-labels may have a double focus:

- on ranges of products first, which allows to provide rather precise but sometimes specialised rules.

- on a given geographic area (country, group of countries, continent). 
Therefore, it is important to understand that even if they can include common principles, ecolabels cannot be compared with a strict sense. Nevertheless, many of the oldest and best known eco-labels concern electronic devices, since their short life duration is at the origin of important problems in reuse and recycling. On this type of products, it is easier to see the common points but also the differences between eco-labels.

Nevertheless, in WEPSI ${ }^{1}$ and (Gallastegui, 2002) can be found interesting comparisons between general purpose eco-labels, which can be applied to various products or services:

- the German Blue Angel eco-label (RAL-UZ 78, 2004), the pioneer eco-label which is at the origin of most of the more recent ones (Jordan et al., 2003),

- the Austrian eco-label (Mol et al., 2000),

- the Nordic Swan eco-label (Nordic eco-labeling, 2002),

- the European Eco Label Scheme (CEC, 2000),

- the Japanese PC Green Label system (PC 3R, 2006).

Under different forms, these eco-labels can be considered as having the following generic content:

1. Introduction, stating the basics of the eco-label,

2. Guidelines for Product design

2.1. Design principles

2.2. Design for waste reduction and for reuse of the product and its components

2.3. Design for disassembly and recycling

2.4. Consistence with a retirement national system

3. Characteristics of the materials and components

3.1. Simplification of the content of materials

\footnotetext{
${ }^{1}$ http://www.recyclingadvocates.org/wepsi/about/finmkt.htm
} 


\subsection{Contamination of recyclable materials}

3.3. Use of recycled and recyclable materials

4. Services linked to the product retirement and recycling

5. Furniture of information and data for end of life management

5.1. Instructions to users concerning end of life

5.2. Information for end of life managers

5.3. Materials labeling

6. Methods for getting continuity in conformance

Certification of an environmental management system

In some cases, other points are considered, like the product installation and the way competent installers are recognised (European Union, 2005).

\subsection{Problems for using eco-labels}

Like the other standards and norms, eco-labels are written in natural language, and may sometimes be difficult to interpret. Moreover, the scope of the subjects addressed is very wide and there is a real need for a step-by-step approach for coping with the eco-label (Seidel et al., 2006). For (Michelini et al., 2004), design frames and diagnosis aids are also required in order to allow to establish life-cycle visibility as requested by eco-labels. (Rosemann et al., 2004) also notice that actual IT-tools are necessary to facilitate the development work; similarly, (Kobayashi et al., 2005) emphasise the need for tools allowing to collect data and calculate the eco-efficiency of the product.

For (Pujari et al., 2006), the problem is not limited to the availability of IT-tools: they established after a questionnaire that the success of development of greener products depends mainly on the availability at each stage of an environmental specialist sharing his knowledge with the design 
team. This is consistent with case studies which also conclude that in spite of the methodological help indirectly provided by the eco-label, competence on environmental issues is necessary, and must be acquired during the process if not available at its beginning (Seidel et al., 2006).

We shall provide in next section a short panorama on the tools already suggested in order to support a sustainable product design.

\section{Methods and tools for eco-design: a panorama}

The various aspects of the life cycle of an eco-design project are addressed by multiple pieces of software; interesting information on these products can for instance be found in (Barnabé et al., 2003 or Vezzoli, 1999). Roughly speaking, and even if this classification is sometimes ambiguous, we can classify these support tools according to the categories described in next subsections.

\subsection{Tools for Life Cycle Analysis}

We can for instance list CMLCA (Centre of Environmental Science (CML)) ${ }^{2}$, EDIP PC-tool (Danish EPA) ${ }^{3}$, EPS 2000 Design System (Assess Ecostrategy Scandinavia AB) ${ }^{4}, \mathrm{GaBi}$ (IKP, University of Stuttgart and PE Product Engineering GmbH) ${ }^{5}$, KCL-ECO (KCL) ${ }^{6}$, LCAiT (CIT Ekologik) ${ }^{7}$, SimaPro (PRé Consultants) ${ }^{8}$, TEAM $^{\text {TM }}$ (Ecobilan PricewaterhouseCoopers $)^{9}$, Umberto (Institute for Environmental Informatics, Hamburg) ${ }^{10}$ or Green Design Advisor (Motorola - University of Erlangen) (Feldmann et al., 1999).

\footnotetext{
${ }^{2}$ http://www.leidenuniv.nl/interfac/cml/ssp/software/cmlca/index.html

${ }^{3}$ http://www.mst.dk/activi/08030000.htm

${ }^{4}$ http://www.assess.se/

${ }^{5} \mathrm{http}: / /$ www.gabi-software.de

${ }^{6}$ http://www.kcl.fi/eco/index.html

${ }^{7}$ http://www.lcait.com/01.html

${ }^{8} \mathrm{http}: / /$ www.pre.nl/simapro/default.htm

${ }^{9} \mathrm{http}: / / \mathrm{www}$.ecobalance.com/fr_team.php

${ }^{10}$ http://www.umberto.de/english/index.htm
} 
These tools address the whole product life cycle and provide databases allowing to assess the impact of a given parameter on the environment. They are more dedicated to an environmental specialist than to the designer himself, even if some of them, like SimaPro or Green Design Advisor, allow the comparison of several design solutions on environmental criteria (Vezzoli, 1999).

\subsection{Screening systems}

These pieces of software, simpler than previous ones, allow a rough assessment of the environmental impact of a product using pre-defined marks included in a database. Typical products are EcoScan (TNO Industrial Technology) ${ }^{11}$, ECO-it (Pré Consultants) ${ }^{12}$ or GEMIS (Global Emission Model for Integrated Systems) (Öko-Institut) ${ }^{13}$.

\subsection{Design for Disassembly}

These systems are closer to practical problems of recyclability, like ATROiD (LCE Consulting, LG-PRC et IWF) ${ }^{14}$, Demrop (Thomas et al., 1996), AMETIDE (CDGM-Renault-Laboratoire $3 \mathrm{~S})^{15}$ or ReGrEd/display (Feldmann et al., 1995) which allows to optimise a disassembly process. ReStar (Carnegie Mellon University) (Navin-Chandra, 1993) allows not only to generate disassembly routings but also to analyse at each step the best strategy between disassembly, grinding, sale or elimination.

\subsection{Material recyclability}

SFB392 (University of Darmstadt) ${ }^{16}$ includes an "expert in recycling” who informs the designer about the requirements of the valorisation channels. ELDA (TNO - University of Stanford National Science Foundation) (Rose et al., 2000) can be linked with a CAD-CAM system

\footnotetext{
${ }^{11}$ http://www.ind.tno.nl/en/product/ecoscan/

12 http://www.pre.nl/eco-it/default.htm

${ }^{13} \mathrm{http}: / /$ www.oeko.de/service/gemis/en/index.htm

${ }^{14} \mathrm{http}: / /$ www.atroid.com

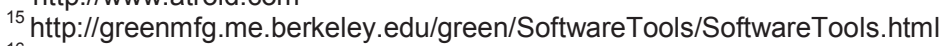

${ }^{16}$ http://www.sfb392.tu-darmstadt.de/
} 
(ProEngineer) and suggests, for each product, an optimal policy between re-manufacturing, reuse of components, material recycling or grinding. IDEmat (University of Delft) ${ }^{17}$ is a data base more oriented on the choice of materials with a low environmental impact. RECREATION (IPAFrankfurt Institute) provides a data base including information on the recycling process and on the suppliers of recycled materials.

It can be seen that these support systems cover various steps of the product life cycle, but are not dedicated to eco-labels, even if most of them address issues also included in eco labels, through the topics of disassembly or compatibility between materials for instance. Nevertheless, they are relatively "closed" since they are based on a given knowledge model linked to eco-design. This is not consistent with the domain of eco-design, in which the product or country targeted leads to select an eco-label - and so a knowledge-base - among others.

Our study has so far been based on the following statements:

- eco-labels can provide a competitive advantage for nowadays manufacturers, at least for the important market of developed countries,

- it should be possible to decrease both the effort and the competence required for the award of an eco-label by providing IT-tools allowing a partial automation of the diagnosis process between an existing or in-design product and the design rules included in an ecolabel. This should be of special interest for SMEs in which environmental competence is a scarce resource,

- in that purpose, we suggest first to analyse relevant eco-labels in order to define an "enriched view" of the product including the data relevant to sustainability,

- we suggest then to translate the rules included into eco-labels into constraints which will be propagated into the product model thanks to available constraint-propagation languages. 
These steps will be described in the next sections.

\section{A product model for eco-design}

A first study allowed us to extract from a sample of eco-labels (mainly those listed in section 2.3) the characteristics of the product allowing to address points 1, 2 and 3 of an eco-label, i.e. issues related to disassembly and recyclability. This data extraction has been described with more details in (Houé and Grabot, 2007a) and the translation of the corresponding sections of the ecolabels into constraints has been illustrated on a simple example in (Houé and Grabot, 2007b). In the following, we shall focus on the different product views allowing to address all the sections of an eco-label, including a "usage" view which is of prime interest for the most recent eco-labels. The application of constraints extracted from an eco-label will then be illustrated on a realistic example of the literature.

We have chosen the ORM language (Halpin, 1999) to describe the product model for several reasons:

- it is close to the entity-relationship model, and so to the class-model of object oriented modeling methods which are now widely used,

- it adds to other languages like UML the possibility to express information by simple relationships (the roles) allowing to verbalise the universe of discourse in a very synthetic way,

- it includes the possibility to describe business rules or constraints, which is of prime interest for our study.

The main notations of ORM are summarised in Table 1.

<insert Table 1. Main ORM notations around here> 
The Knowledge Based Engineering (KBE) provides interesting advanced techniques allowing to capitalize and re-use knowledge, especially for the integrated design of a product (Saucier, 1996; Yvars, 2001). In order to define our extended product model, we have taken as a base the model suggested in (Harani, 1997) since this model introduces concepts which can be of interest for our study:

- $\quad$ each product can have different parameters (for us, nature of the material, mass...),

- a point of view can be defined by one to several nodes, to which may be associated products,

- a link (denoting composition, specialisation or equivalence) can be defined between two nodes.

Nodes and links can so describe a physical decomposition of products (e.g. in the bill of materials) through composition links, but also a logical association of products like products participating to the same function, through specialisation links,

- nodes and links can have parameters; a parameters can concern several nodes or links. Therefore, nodes and links can be used in our case for describing not only the "physical" structure of a product (e.g. its bill of materials) but also other ways to group the components of a product: components including plastic parts, components including hazardous substances, etc.

Four points of view are considered on the product in the following, namely:

- its structure; which provides the classical model of a product, allowing for instance to describe a bill of materials,

- its recyclability, allowing to deal with the criteria concerning the nature of materials contained in a product,

- its disassembly, in order to provide the data required for assessing the corresponding criteria described in the standards, 
- its usage, grouping data related to its installation, to its consumption (electricity, etc.), emissions (noise, radiations, gas...) and to the service provided during its life (manuals, maintenance, etc.).

- This way to divide the problem integrates most of the recycling guidelines: see for instance (Bras, 2006) which considers three categories: Component design, Material selection and Fastener selection.

For a better readability, we have chosen to describe separately these four points of view, although they can be gathered using Harani's concepts.

\subsection{Structural point of view}

The structural point of view is shown in <insert Figure 1. The central concept of the model is the "product", which can itself be composed of products i.e. individual components of the whole product ("assembly" role at the top of $<$ insert Figure 1). A product can be a node (it plays then the role "product-node"). A link can be defined between two nodes, with a beginning and an end node (bottom-left role). Parameters can be associated to nodes, links or products.

Harani defines a "qualitative" parameter on the base of the entity "description" and a "quantitative" parameter on the base of the entity "parameter". In order to be more generic, in the

model of $<$ insert Figure 1 is introduced the object "parameter" from which inherits the qualitative and quantitative parameters. A "level_product" entity has also been added in order to express that a product can be a final product, a sub-assembly, a module, a component or a “product_assembly", defined here as a product allowing to gather other products (screw, box...). These various categories are required for the interpretation of some of the constraints present in the standards, roughly described in section 2.3 . 
We have chosen VisioModeler ${ }^{\mathrm{TM}}$, a free software, for designing the ORM models. A window can be noticed at the bottom of $<$ insert Figure 1: by clicking on a role or on a link, a window, named "verbalizer", appears and provides a semantic interpretation of the clicked entity. This is another illustration of the expressivity of the ORM model, which is of great help for validating the model. The right window explains the "assembly" role, whereas the left window explains the "dot" present on the two links denoting that the role is mandatory.

<insert Figure 1. Structural point of view around here>

\subsection{Recyclability point of view}

The recyclability point of view is shown in <insert Figure 2 . The main additions to the structural point of view are the followings:

- a product is made of a given material, which is a critical point regarding the recyclability issue. Especially, some classes of materials (see bottom entity “class_material”) prevent from an efficient recycling (Cu-alloys, Al-alloys, PVC...). Also, some materials are not mutually compatible, according to tables of compatibility already mentioned (“material_compatibility_table" entity, left bottom corner), the best known being included in the norm VDI 2243.

- as stated before, some substances are often added to a product during its manufacturing, like painting or varnish. Recyclability also requires to precisely identifying each part included in the product, either through marking (see top-left role) or labels. Since many criteria of the standards specifically concern these additional materials, we have preferred to define a specific entity named "substance" concerning these additional products. Incompatible substances are also described in a table (bottom left of $<$ insert Figure 2).

<insert Figure 2. Recyclability point of view around here $>$

\subsection{Disassembly point of view}


The disassembly point of view complements the previous one: as seen in section 2.3 , some criteria included in the eco-labels aim at verifying that the dismantling of the product is possible and easy with common tools and competences.

<insert Figure 3. Disassembly point of view around here>

A product (top right entity) can be disassembled according to a disassembly process requiring resources which can be machines, tools or operators (bottom entities). All these resources are described according to parameters which will allow to check the satisfaction of the criteria included in the standards (e.g. tools must not be specific, an operator with a common competence must be able to perform the disassembly process, etc.).

\subsection{Usage point of view}

The model describing the "usage" point of view (<insert Figure 4) is rather different from the previous ones, since it has to be much more flexible in order to be possibly applied on rather different products. Therefore, it will be described with more details than the previous ones. It is also worth to notice that this view may refer, among other data, to the instructions or manuals the manufacturer has to provide with the product in order to make the user aware of some damage the use of a product may cause to the environment.

Two main kinds of object have been identified in the "usage" point of view: the "usage function" of a product and the "usage function type" to which a "usage function" belongs. According to the modeling formalism chosen for this study, we have translated the "use" criteria through the following facts:

- "Usage function" belongs to "usage function type"

1. Examples of "usage functions": sleep mode, off mode, energy efficiency, default mode change, power supply, noise level. 
2. Examples of "usage function types": energy saving, natural resource saving, limitation of the use of detergents, noise lowering, electromagnetic emissions lowering, instructions to the user.

3. The previous examples of usage functions belong to the usage function type "energy saving".

- "Product" has "usage function"

1. Examples of product: computer, computer processing unit (CPU)

2. Examples of criteria:

- Personal computers: "the computer shall support the ACPI S3 sleep state (suspend to RAM) $<=4$ w".

- Portable computers: "the computer shall have an off mode consumption $<=$ $2 W^{\prime \prime}$.

- Refrigerators: "the appliance must have an energy efficiency class of A+ or A++ as defined in Directive 94/2/EC, and amended by Directive 2003/66/EC".

- "Usage function" may have "parameter"

1. Examples: "power consumption" is a parameter of the usage function "sleep mode", "time" is a parameter of the "mode change", "consumption" is a parameter of the "off mode", "class" is a parameter of the "energy efficiency", etc.

2. Examples of criteria

- Personal computers: "the monitor shall have a sleep mode power consumption lower than $2 \mathrm{~W}^{\prime}$.

- Portable computers: "the portable computer shall have an off mode consumption lower than $2 \mathrm{~W}^{\prime}$.

- Refrigerators: "the appliance must have an energy efficiency class of $\mathrm{A}+$ or $\mathrm{A}++$ as defined in Directive 94/2/EC, and amended by the Directive 203/66/EC". 
- "Usage function" may concern "directive reference"

1. Examples of references: "Directive 94/2/EC", “2003/66/EC”, "VDI-2243”.

2. Example: the usage function "energy efficiency" must comply with the reference “Directive 94/2/EC, amended by Directive 2003/66/EC" (see refrigerators ecolabel).

<insert Figure 4. Usage point of view around here>

Let us remind that the concept "product" (defined in the structural point of view) stands for an individual component or article defined in a Bill Of Material but also for the whole product itself, whereas "reference" (defined in recyclability point of view) stands for a norm or a standard.

In order to be able to quickly assess the recyclability of product, it is necessary to translate norms related to this issue into exploitable form. For that purpose, we have shown in previous sections that the ORM formalism is a good choice for us, aiming at extracting data that are needed for the recyclability analysis. In that purpose, we have described the relations between these data (typical to the recyclability issue) and those classically required during the design of product. As result, we have defined an extended product model based on the Harani's structural model (Harani, 1997), and completed by some data which may correspond to technological choices and which particularly relate to (i) the disassembly, (ii) the recycling and (iii) the usage of product. The problem for the designer is then to find the choices which comply with these environmental requirements.

In the following, we will first describe the translation of rules into constraints. An application to an example product design will be presented thereafter.

\section{From rules to constraints}


In the literature, the design activity could be defined as a sequence of models transformation: from the model of functionalities i.e. the projection of the artefact specifications (O'Sullivan and Bowen, 1998) to a model of the artefact structure, and thereafter to the model of technological choices.

According to Chandrasekaran (Chandrasekaran, 1990) "the design problem is specified by (i) a set of functions to be delivered by an artefact and a set of constraints to be satisfied and (ii) a technology, that is, a repertoire of components assumed to be available and a vocabulary of relations between components". In the context of product design, constraints based approach seems more and more promising (Hadj-Hamou, 2002; O’Sullivan, 1999; Vareilles, 2005). One can classify constraints into two main categories (Janssen, 1990): constraints of validation (those related to the specifications), and constraints of preference (those specific to customer requirements). In this study, the environmental requirements, characterised by the rules defined in norms, could be associated to these last kinds of constraints.

Let us precise that we do not focus on the design activity itself: within the framework of our study, we firstly need to formalise data related to the recyclability analysis which could be difficult to extract by the designer from their initial sources (i.e. the rules of norms); secondly, we want to assess the compliance of the specifications with environmental constraints. In that context, the knowledge on the design is already available. In other words, we are more specifically interested by an issue close to the scope of a configuration which can be defined (Mittal and Frayman, 1989; Aldanondo et al., 2000) as "finding at least one component set that satisfies all the constraints, given (i) a generic model of configurable product to be able to represent a family of product, and (ii) a set of customer requirements". We assume that our proposed extended model is a generic model which represents a family of product, and that the rules extracted from norms are "customer" requirements (in the sense of the definition of configuration). 
The CSP approach offers suitable framework of solving configuration problem. Let us first present some basic definitions related to it.

\subsection{Preliminary definitions}

A CSP is fundamentally composed of a set of variables, each associated with a domain, and a set of constraints. The task, especially during the design of product, is then to assign a value to a variable (when needed) and thereafter check if it is consistent with all the constraints. The sets of variables and constraints could be theoretically infinite, but in practice, the majority of the sets of variables and constraints in CSP are finite, which is naturally the case for our study.

A variable is basically a data considered in the constraints problem (for instance, the mass of a component, the material it is made of, the number of tools required to disassemble a product, etc.). The domain of a variable describes all the possible values that can be assigned to this variable. When a variable can only be assigned to numbers, it is called a numerical variable (for instance, the mass of a component). When the domain contains an enumerated type of objects, the variable is called symbolic variable (for instance the family of material that compose a component could be "plastic", "ceramic", "metal", etc.). These are the two main kinds of domains of variables that are common to the majority of CSPs. Let us add that numerical variables could be transformed into symbolic ones (see Faltings, 1994): for instance, the variable "mass" of a component has been specifically considered in this study as a symbolic one (according to our interpretation of the associated rules). Indeed, following to the requirements prescribed in eco-labels, some rules need to take into account the case of which a component is "over $25 \mathrm{~g}$ " weighted, so that the possible values we have defined for the variable "mass" are "over $25 \mathrm{~g}$ " and "less than $25 \mathrm{~g}$ ". 
A constraint on a set of variables is a restriction on the values that they can take simultaneously. In some cases, mathematical conventions can be used to describe the relationships between (constrained) variables: these are numerical constraints (for instance, the volume of a tank is a well known mathematical relationship between the radius of the tank and its height). However, especially in this study, all the constraints are defined as sets which contain the legal combinations of values that some variables can take simultaneously: these kinds of constraints are generally presented in the form of tables of compatibility between admitted values (of the constrained variables). The main task for us has been to translate rules, initially described in a natural language form, into such tables (of compatible values).

Based on these preliminary definitions, one can formally define a CSP as follows.

\subsection{Formal definition of CSP}

Definition: A Constraint Satisfaction Problem (CSP) is a triple $\prec X, D, C \succ$ (Montanari, 1974), where:

- $\mathrm{X}=\left\{\mathrm{x}_{1}, \ldots, \mathrm{x}_{\mathrm{n}}\right\}$ is a (finite) set of variables,

- $\mathrm{D}=\left\{\mathrm{Dx}_{1}, \ldots, \mathrm{Dx}_{\mathrm{n}}\right\}$ is a (finite) set of variable domains, one for each variable,

- $\quad \mathrm{C}=\left\{\mathrm{C}_{1}, \ldots, \mathrm{C}_{\mathrm{m}}\right\}$ is a (finite) set of constraints on an arbitrary subset of variables in $\mathrm{X}$.

Each constraint $C_{i}$ is defined as a relation $R$ on a subset of variables $V=\left\{x_{i}, \ldots, x_{k}\right\}$, called the constraint scope. R may be represented extensionally as a subset of the Cartesian product $\mathrm{Dx}_{\mathrm{i}} \times \ldots \times \mathrm{Dx}_{\mathrm{k}} . \mathrm{A}$ constraint $\mathrm{C}_{\mathrm{i}}=\left(\mathrm{V}_{\mathrm{i}}, \mathrm{R}_{\mathrm{i}}\right)$ limits the values the variables in $\mathrm{V}$ can take simultaneously.

Considering a subset $\mathrm{V}_{\mathrm{K}}=\left\{\mathrm{x}_{\mathrm{k} 1}, \ldots, \mathrm{x}_{\mathrm{k} 1}\right\}$ of $\mathrm{X}$, an 1-tuple $\left(\mathrm{x}_{\mathrm{k} 1}, \ldots, \mathrm{x}_{\mathrm{k} 1}\right)$ from $\mathrm{Dx}_{\mathrm{k} 1} \times \ldots \times \mathrm{Dx}_{\mathrm{k} 1}$ is called an instantiation of variables in $\mathrm{V}_{\mathrm{K}}$. An instantiation is said to be consistent if it satisfies all the constraints restricted in $\mathrm{V}_{\mathrm{K}}$. A consistent instantiation of all variables in $\mathrm{X}$ is a solution. 
The task of solving a CSP is then to find one or more solutions. In many constraints-related applications, particularly in this study, the constraints network changes as and when a decision is made i.e. when an instantiation occurred. This characterises a particular type of CSP which will be defined later. Let us first illustrate a CSP modeling on an example.

Example: Let us for instance consider the following requirement extracted from the Blue-Angel eco-label: "Plastic parts over $25 \mathrm{~g}$ must be marked according to ISO 11469 ”. We have defined a constraint between the variables "identification_mode" (of which possible values are "marking", "labeling" that are examples of mode for identifying a component) and "identification_reference (of which possible values are "ISO 11469", "VDI 2243" that are examples of environmental standards related to component identification). According to CSP modeling, the previous rule states that the value "marking" of the variable "identification_mode" is compatible with the value "ISO 11469" of the variable "identification_reference" (see the right part of <insert Figure 5). The rule also states that this compatibility is verified only if the component is made of plastic and is over $25 \mathrm{~g}$ weighted. We have then decided to add a predicate aiming at defining condition that will allow the constraint between the variables "identification mode" and "identification_reference" to participate to the verification of the whole network of constraints: the values "> 25g" and "plasic" have to be assigned in their respective variables. We have so specified in the CSP model that the variable "identification_reference" is active (i.e. participate to problem solving) if this predicate is true, otherwise the constraint between "identification_mode" and "identification_reference" is always satisfied (i.e. not necessary to be checked). As described previously, the predicate (that condition the activation) has allowed to add a variable (i.e. make it active) to the problem, but in some other cases, a variable or a constraint could be deleted (i.e. made inactive).

<insert Figure 5. Identification of plastic components around here > 
This example characterizes a specific kind of CSP called Dynamic CSP (see Mittal and Falkenhainer, 1990) that could be informally defined as a set of variables and constraints in which variable assignments determine whether parts of problem (variable or constraint) are active or not.

Considering a CSP $\prec X, D, C \succ$, any problem of the form $\prec X^{\prime}, D^{\prime}, C^{\prime} \succ$ such that:

- $\quad X \subset X '$ i.e. there are more variables,

- D’x $\subset$ Dx for each variable $\mathrm{x}$ in $\mathrm{X}$, i.e. there are fewer values for variables,

- $\quad$ and C' $\subset \mathrm{C}$ i.e. there are fewer legal combinations for variables in a constraint

is a restriction of $\prec \mathrm{X}, \mathrm{D}, \mathrm{C} \succ$.

In a same manner, any problem of the form $\prec X^{\prime}, D^{\prime}, C^{\prime} \succ$ such that:

- $\quad X^{\prime} \subset X$ i.e. there are fewer variables,

- Dx $\subset$ D'x for each variable $\mathrm{x}$ in $\mathrm{X}$, i.e. there are more values for variables,

- $\quad$ and $\mathrm{C} \subset \mathrm{C}$ ' i.e. there are more legal combinations for variables in a constraint

is a relaxation of $\langle\mathrm{X}, \mathrm{D}, \mathrm{C} \succ$.

A $D C S P$ is then a sequence of $C S P$ such that each problem in a given step is either a restriction or a relaxation of the problem of the previous step, in other words, one is allowed to add or remove variables, and also to modify the set of constraints.

The original formal definition of DCSP (Mittal and Falkenhainer, 1990) is the following.

\subsection{Formal definition of DCSP and example of our study}


Definition: An instance of DCSP is of form $\prec \mathrm{X}, \mathrm{D}, \mathrm{X}_{\mathrm{I}}, \mathrm{C}_{\mathrm{C}}, \mathrm{C}_{\mathrm{A}} \succ$ where

- $\mathrm{X}=\left\{\mathrm{x}_{1}, \ldots, \mathrm{x}_{\mathrm{n}}\right\}$ is the set of variables (for instance the four variables in <insert Figure 5 ),

- $\quad \mathrm{D}=\left\{\mathrm{D}_{1}, \ldots, \mathrm{D}_{\mathrm{n}}\right\}$ is the set of domains of the variables, $\mathrm{D}_{\mathrm{i}}=\left\{\mathrm{d}_{\mathrm{i} 1}, \ldots, \mathrm{d}_{\mathrm{ij}}\right\}$ are the values in the domains,

- $\quad \mathrm{X}_{\mathrm{I}}(\subset \mathrm{X})$ is the set of initial variables (the variables at the left side of <insert Figure 5),

- $\mathrm{C}_{\mathrm{C}}$ is the set of compatibility constraints (for instance the compatibility between the two variables at the right side of $<$ insert Figure 5 that stipulates that the value "Marking" is compatible with the value "ISO 11469"),

- $\mathrm{C}_{\mathrm{A}}$ is the set of activity constraints (for instance, in the example of $<$ insert Figure 5 , the activity constraint of this little problem specifies that if and only if the variables “comp_mass" and "material_family" are respectively assigned the values " $25 \mathrm{~g}$ " and "plastic", then the variable "identification_reference" is activated.

The constraints network of our study: According to the previous definitions, our study could be formalised as a DCSP characterised by around 25 variables (with their respective domains) of which $\mathbf{1 4}$ are initially active (those with dotted boundary in <insert Figure 6). The variables and their associated constraints are classified according to their belonging to the "structural", "disassembly", or "recycling" points of view that have been earlier defined in this paper. We have also defined 18 compatibility constraints with 11 activation constraints.

Let us mention that some rules of eco-labels cannot be easily formalised with the CSP concepts: we have considered them as simple questions in the form "YES/NO". As illustrated in the middle bottom of <insert Figure 6, they do not have any link with the (D)CSP of our problem itself. We have done the same when analyzing the rules of eco-labels that relate to the "usage" point of view. 
It is also worth to notice that all the constraints of our problem are binary, and that the activity constraints induce only adding new variables (there is no case of deleting variables).

<insert Figure 6: The constraints network of the study>

\subsection{Search of solution(s) and constraint programming}

A configuration task could be performed through two main manners: (i) autonomously (case of autonomous configuration) or (ii) interactively (case of interactive configuration). The first type of configuration consists in finding at least one solution (for example using backtracking methods). The second type of configuration consists in reducing progressively the domain of the solutions, based on the designer choices. The framework of our study is closed to this last case. Indeed, we assume that the "initial" design of the artefact (the constraints of validation) is made; by entering some parameters, the designer will check if the specifications of the artefact comply with environmental requirements (i.e. the constraints of preference).

In interactive configuration, the search is generally performed with filtering based methods, for instance arc-consistency algorithms which are particularly suitable for binary constraints (Mackworth, 1977). As stated previously, all the constraints of our case study are binary, so that arc-consistency algorithms seem to a good choice for us. We have particularly used AC-3 which is one of the most simple but powerful one.

According to the previous definition of configuration, there is a need for a highly expressive language in order to model our problem. A declarative paradigm language seems to be suitable for that purpose. The Constraint Logic Programming (CLP) is of such paradigm which allows to describe real-world problems by using constraints (Rossi, 2000). The author precise that constraint-based language offers many advantages: (i) the direct representation of problem in 
terms of constraints reflects to simple and short program, (ii) the high level of its expressiveness gives the right level of abstraction for the programmer, (iii) the program can be quickly written and modified so that it can be possible to quickly check various manners of solving a problem. CHIP (Dincbas et al., 1998) is an example of language based on this paradigm: some CHIPrelated languages are for instance the constraints handling libraries provided by ILOG (ILOG, 1996) and COSYTEC (Freuder, 1996), some other CLP-languages are PROLOG III (Colmerauer, 1990), CLP(R) (Jaffar et al., 1992), ECLipSe (Wallace et al., 1997), CIAO (Hermenegildo and the CLIP group, 1994), clp(fd) (Codognet and Diaz, 1996).

An important prerequisite of our study is that the system aiming at providing support to the designer must be able to extract some needed data directly from existing systems such as CADsystems: in order to insure that the recyclability assessment is consistent with the "initial" detailed specifications of the artefact, these data do not need to be redefined. Thus, it is necessary to interact with existing systems. For that purpose and others which are discussed in the following, we have preferably used the CLAIRE language which also allows to suitably model constraints-related problems.

\subsection{Expressing environmental rules through constraints in CLAIRE}

CLAIRE (Combining Logical Assertions, Inheritance, Relations and Entities) ${ }^{18}$ is a high level open source language providing a set of orientations of great interest for our study, among which object orientation, description of concrete or abstract sets, or production rules (Caseau et al., 1996). In order to manage databases, a layer has been recently added to the core system: Webclaire. Another interest of CLAIRE is that it provides an easy way to write facts describing the membership of an element to a set, and so to manipulate for instance lists of forbidden substances or materials. It is so very easy to modify such facts, by updating the list of the elements of a set.

\footnotetext{
${ }^{18} \mathrm{http}: / /$ claire3.free.fr/
} 
Even if this programming language is not a constraint propagation language on its own, it allows to easily describe constraints, especially using CHOCO, a library written in CLAIRE and dedicated to constraint programming, including dynamic constraint satisfaction. Among the tools of constraint propagation, arc consistency (see for instance Dechter, 2003) allows to check whether the values of variables located on nodes or links of a graph are consistent with a constraint, which allows to process most of the constraints identified in the eco-labels considered in this study. A short description on how constraints are modelled in CLAIRE is provided in the following.

\subsection{Results}

Of course, this translation of rules into constraints can only be done for well structured/quantitative rules. In the eco-labels, qualitative rules are also present which would be very hard to express through constraints. Therefore, we have decided to address these rules through an interaction with the user, our aim being to provide support and not to fully automate the checking process.

On the Blue Angel eco-label (with its application to computers, see RAL-UZ 78, 2004), which is certainly the more representative, our experiment of translation of rules into constraints has given to the following results:

In Blue Angel, a first set of rules deals with global aspects of the product; these rules are grouped in three categories:

- Structure and Connection technologies,

- Material Selection and marking,

- Longevity and upgradeability. 
Structure and Connection technologies contain 12 rules; 9 of them were easily translated into constraints whereas the remaining 3 were to be processed by questions to the users (for instance "Have necessary points of application and working space been taken into account for disassembly tools?").

Material Selection and marking contains 8 rules. 4 were translated into constraints, 4 were addressed by questions. It is interesting to notice for instance the subjectivity of questions like "Is the coating of plastic components limited to a minimum?".

Longevity and upgradeability contains 4 very high level questions (for instance "Is the system ready for functional upgrading?"). Only one was expressed by a constraint: "Does the product has a modular design?", since it could be processed considering the bill of materials and description of the connexions between sub-components.

Then, more detailed rules are detailed in the Annex of the eco-label, related to the various components of the computer: system unit, display unit, keyboard. The system unit is for instance addressed by 36 questions, 28 of them having been expressed through constraints. The other components show comparable results.

As a final statement, it is not less than 129 rules (but some of them are the same rules applied to the various modules) which are taken into account in this Blue Angel eco-label, in addition to the 24 high level ones. As a final result, 95 rules were expressed by constraints, which represent $75 \%$ of the rules. Experiments conducted using the Nordic Swan eco-label showed comparable results. More information on the way to translate rules into constraints can be found in (Houé and Grabot, 2007b). We shall see in next section how constraints extracted from eco-labels can be propagated in a product model instantiated from the generic models described in previous section.

\section{Application to an example of the literature}


An example of the literature has been used to validate the proposed methodology: it is based on a Computer Processing Unit (CPU). This example has been created in order to assess environmental requirements focusing on the ease of disassembly (see Kroll and Hanft, 1998). This corresponds, in our case, to the "disassembly" point of view of the proposed extended product model (see <insert Figure 3).

We have chosen to consider the compliance of this product with the official European eco-label concerning personal computers ${ }^{19}$, even if this eco-label is more oriented on portable computers. Some points of the instantiation of the product model will be described first. The result of the propagation of the constraints extracted from the first assessment check-list of this label will then be discussed.

\subsection{The European eco-label}

The check list for first assessment of the European eco-label on portable computers is composed of the following rules:

\section{Manufacturing:}

M1: plastic parts heavier then $25 \mathrm{~g}$ shall not contain flame retardant substances (...) assigned to the following risk phases R45 (...) as defined in Council Directive 67/548EEC and its amendments. M2: plastic parts shall not contain PBB or PBDE flame retardants nor chloroparaffin flame retardants with (...)

M3: the background lighting of the LCD monitor shall not contain more than $3 \mathrm{mg}$ of mercury on average per lamp M4: batteries shall not contain more than $0,0001 \%$ of mercury (...)

\section{Use:}

energy saving 
U1: the CPU meets the energy star configuration requirements

U2: the computer shall support the ACPI S3 sleep rate $(\ldots) \leq 4 \mathrm{~W}$

U3: the default mode change time from operation to the ACPI S3 sleep rate $\leq 30 \mathrm{mns}$

U4: the portable computer shall have an off-mode consumption $\leq 2 \mathrm{~W}$

U5: the portable monitor shall have a sleep mode power consumption $\leq 2 \mathrm{~W}$

U6: the portable monitor shall have a default mode change time $(\ldots) \leq 30 \mathrm{mns}$

U7: the portable monitor has an off-mode consumption $\leq 1 \mathrm{~W}$

U8: the portable monitor does not exceed the energy star v.4 requirements for (...)

\section{instructions}

U9: information on the use of the power management features (...) must come with the product U10: information on the zero energy consumption if the power supply is unplugged or (...) must come with the product

U11: information on the availability of spare parts must come with the product

U12: information on the parts of the computer designed to be recycled or reused must come with the product

U13: information on the appropriate use of WI-FI cards to minimize security risks must come with the product

noise

U14: noise $\leq 40 \mathrm{~dB}(\mathrm{~A})$ in idle operating mode

U15: noise $\leq 45 \mathrm{~dB}(\mathrm{~A})$ when accessing a hard drive disk

electromagnetic emission

U16: the portable computer shall meet the requirements (...) EN50279, Category A 
E1: easy dismantling and disassembling by one qualified person alone

E2: $90 \%$ by weight of plastic and metal material recyclable

E3: plastic parts shall have no added lead or cadmium that cannot be separated easily and have a permanent marking (...) conform to ISO11469:2000

E4: hazardous materials shall be easily separable

E5: labels are easily separable or inherent

E6: free of charge take-back (...) is provided

E7: Information on take-back policy is provided

E8: all packaging components shall be easily separable by hand (...)

E9: cardboard packaging shall consist of at least $80 \%$ recycled material

E10: the computer shall be designed so that memory and card graphic are easily accessible and can be changed

E11: (...) the hard disk, CD driver or DVD drive can be changed

We shall now describe our candidate product.

\subsection{Instantiation of the product model}

The product depicted in this example is shown in $<$ insert Figure 7. An associated rough bill of materials is shown in Figure 8.

<insert Figure 7. Drawing of the CPU (Kroll and Hanft, 1998) around here>

In order to analyse the compliance of this product with the eco-label, we have specifically focused here on two of the views of our model: disassembly (using the data present in Kroll and Hanft, 1998), and usage, after addition of classical data on such type of product.

The structural view is based on the bill of materials (BOM, which examples of individual components are "font bezel", "housing", "motherboard", "power supply", etc. (see Figure 8) to 
which are added data related to additional component which are usually not described in the BOM (glue, labels, connectors...). The main problem encountered with the data related to this view is that those present in (Kroll and Hanft, 1998) do not mention the variable "product_mass" that is needed for example in the criterion illustrated in <insert Figure 5. Therefore, we have replaced the obsolete "floppy disk drive" by a DVD and complemented the available data with classical ones concerning glue, labels connectors and mass in order to have all the required information.

Figure 8. Simplified bill of materials of the CPU (Kroll and Hanft, 1998).

It is interesting to notice that the data related to the variable "material_family" defined in the structural view are provided with the CPU example. This variable is specifically needed to check the compatibility between components that belong to the same structural node.

The recyclability view of our model is nevertheless not of a great interest in the case of the CPU: as illustrated by the data provided in (Kroll and Hanft, 1998), the components are suitably connected (i.e. allowed materials and parts made of homogeneous plastics); moreover, appropriate labeling seems to be used as identification mode of the product. Thus, we will in the following only focus on the disassembly and the usage points of view.

\section{Disassembly data}

Even if the quick check list of the considered eco label has only very basic requirements concerning disassembly, we have instantiated in the model all the available information provided in the example. This information can for instance be useful to assess the "facility" of an operation (which may for instance be defined as depending on the type of tool used), or the variety of tools required for disassembly. These concepts correspond to the ORM object "disassembly_process" as defined in our proposed model of which the concern "structural" point of view is depicted in $<$ insert Figure 3. 
Some occurrences of "task" (i.e. "disassembly_process" in our model) extracted from the example of product we have used are (as defined in Kroll and Hanft, 1998): "unscrew", “remove”, “hold/grip”, “peel”, “turn”, “flip”, “saw”, “clean”, “wedge/pry”, “deform”, “drill”, "grind”, “cut”, "push/pull”, "hammer”, “inspect”.

As stated in section 4.3, the ORM object "resource" in our model is a generic concept that could be a disassembly "tool", a human "operator" in charge of disassembling the product, a "machine" or even a workstation where the disassembly activity should take place.

Some occurrences of disassembly "tools" extracted from the example are:

- For the unscrewing tasks: "Philips screwdriver", "flathead screwdriver", "nut driver", “fixed-end wrench", “adjustable wrench”, "socket with ratchet”, “Allen key”, “power wrench".

- For the gripping/fixturing tasks: "vise", "pliers".

- For the cutting/breaking tasks: "knife", "wire cutter", "handheld shears", "drill”, "handheld power grinder”, “grinding wheel”, “hacksaw”, "power saber saw”, “power ban saw", "hammer", “chisel”, "prybar".

- For other tasks: "brush", "rag”, "special tool”.

We have then associated difficulty rates to these various tools.

\section{Usage data}

It is obvious to notice that an object of a given view of our model could link to objects of another view. In that case, thanks to VisioModeler ${ }^{\mathrm{TM}}$, it is represented with a double ellipse (as illustrated in <insert Figure 1, <insert Figure 2, <insert Figure 3, and <insert Figure 4). It appears then that the ORM objects "usage_function" and "usage_function type" are typical to the usage view. 
According to the "usage_function" corresponding to "instructions to user" of this view, we can for instance define the following variables (with their corresponding domain values):

- "power_consumption": 1- "zero", 2- "low", 3-"high"

- "product_type" (which an instantiation of the ORM object "qualitative_parameter" as illustrated in <insert Figure 1): 1- "power supply", 2- "wall socket", 3- "other"

- "link_state" (another instantiation of "qualitative_parameter"): 1- "plugged", 2"unplugged"

- "product_state" (other instantiation of "qualitative_parameter"): 1- "swiched on", 2"switched off"

- “take_back process" (other instantiation of "qualitative_parameter"): 1- "existing"

Nevertheless, we have voluntarily not provided any information on the packaging of the product, which can be included in the extended BOM of the product like labels, glue, etc.

\subsection{Propagation of constraints in the instantiated product model}

Considering our test case, all the rules typical from a portable computers are not considered (namely $\mathrm{U} 5,6,7,8)$.

M1 and M2 have been processed by checking that all materials described in the BOM were absent from tables of forbidden materials included in the database.

When considering the constraints linked to the compliance with external standards (U1-16; part of E3), the constraint propagation finds that our system is not compliant with Energy Star standard (U1).

All the rules dealing with numerical values are satisfied (M3-4; U2-4; U14, U15, E2). For E2, the system has had to calculate the total weight of the product, and the total weight of recyclable materials. 
Take-back (more precisely the existence of an information regarding the existence of a take back process...) was included in the usage model as a usage function (which is arguable), therefore E6 was satisfied.

All the rules dealing with the availability of instructions were satisfied (U9-13; E7).

None of the constraints considering the packaging are satisfied, since no packaging information has been introduced in the database $(\mathrm{E} 8, \mathrm{E} 9)$

Because of the issue of "accessibility", hardly interpretable, E10 has been addressed by a question to the user, whereas E11 is automated through a constraint taking into account the type of connection used for the hard disk and DVD.

The constraints linked to "easy separation" have been processed considering the type of connector and the dismantling tools (E1; E3-5).

As result of this experiment, the product model suggested has been able to store properly most the required data, whereas only one rule was not easily translated by a constraint (due to the fact that the considered eco-label contains very few qualitative rules). Of course, the result of the propagation has no meaning, since many data have been added on purpose. Nevertheless, it shows in our opinion the feasibility of the method.

\section{Conclusion}

Sustainable development is a major challenge for our society, but its full integration in our behaviours cannot be obtained as quickly as necessary if it is only considered as a new source of constraints for companies. We think on the opposite that, with the emergence of a real customer awareness on environmental issues, the eco-friendliness of a product may become a competitive advantage, allowing to make consistent two apparently conflicting issues, namely sustainable development and law of the market. 
Customers do not have time nor competence for directly assessing to what extend a product is respectful of the environment. Therefore, eco-labels should play more and more the role of certification standards which can be trusted by the customers. The recent literature suggests that obtaining these eco-labels has a real and growing impact on the market, but practical experiences also show that expertise is necessary in order to cope with the numerous and sometimes ambiguous rules contained in the eco-labels.

In order to decrease both the level of competence and the time needed to verify the compliance of a product with an eco-label, we have firstly suggested generic product models allowing to store all the data required by the verification process. We have then shown that it was possible to translate an important part of the rules contained in eco-labels in constraints which can be automatically propagated in instances of these models. Of course, allowing a fully automated analysis of the compliance of a product with an eco-label would require to cope with a small percentage of very qualitative rules which would require a huge modeling and programming effort. Therefore, we have chosen an interactive approach allowing to complete the analysis coming from stored data by external information directly coming from the user.

A software prototype is now running, with a knowledge base addressing 60 to $75 \%$ of the rules contained in three of the most well known eco-labels (Blue Angel, Nordic Swan and TCO (TCO, 2000)). In order to allow a real use of these principles, the following developments are in progress:

- to implement explanation facilities when constraints are not satisfied. According to (McDonald et al., 2002), this could be done using CHOCO with the procedure defined in (Junker, 2001),

- to develop higher level interfaces allowing an efficient interaction between the user and the decision support system, 
- to suggest indicators allowing to synthesise the degree of compliance of a product with an eco-label.

\section{References}

Aldanondo, M., Moynard, G., Hadj-Hamou, K., 2000. General configuration requirements and modeling elements. ECAI Workshop on Configuration, Berlin, Germany, 1-6.

Argument, L., Lettice, F., Bahmra, T., 1998. Environmentally conscious design: matching industry requirements with academic research. Des Stud, 19(1), 63-80.

Barnabé, F, Ganier, M., Lafleur, B., Malosse, R., Moulin, V., Schiesser, P., 2003. L'écoconception pour les mécaniciens, Editions du CETIM, France.

Bras, B., 2006. Design for recycling, part 1, Georgia Institute of Technology, lecture notes available on the web: http://www.srl.gatech.edu/education/ME4171/

Bruce, C., Laroiya, A., 2007. The production of eco-labels. Environmental and Resources Economics, 36(3), 275-293.

Campbell, M. I. Asad, H., 2003. Design Evaluation Method for the Disassembly of Electronic Equipment. International Conference on Engineering Design - ICED 03, August 19-21, Stockholm, Sweden.

Caseau, Y., Laburthe, F., 1996. CLAIRE: Combining Objects and Rules for Problem Solving, Proceedings of the JICSLP'96 workshop on multi-paradigm logic programming, M.T. Chakravarty, Y. Guo, T. Ida Eds., TU Berlin.

CEC, 2000. Regulation (EC) $n^{\circ} 1980 / 2000$ of the European Parliament and of the Council of 17 July 2000 on a revised Community eco-label award scheme, official Journal, L 237 of 21 September 2000, 1-12.

Chandrasekaran, B., 1990. Design problem solving: A task analysis. AI Magazine 11(4), 5971. 
Codogne, P., Diaz, D., 1996. Compiling constraints in clp(fd). Journal of Logic

Programming 27(3), 185-226.

Colmerauer, A., 1990. An introduction to Prolog III. Communication of the ACM.

Dechter, R., Dechter, A., 1988. Belief maintenance in dynamic constraint networks.

Proceedings of the Seventh National Conference on Artificial Intelligence, 37-42.

Dechter, R., 2003. Constraint Programming, Morgan Kaufmann Publishers, San Francisco.

Dincbas, M., van Hentenryck, P., Simonis, H., Aggoun, A., Graf ,T., Berthier, F., 1998. The constraint logic programming language CHIP. In Proc. International Conference on Fifth Generation Computer Systems. Tokyo, Japan.

Dowie, T., 1994. Design for Disassembly. Technical Report, Manchester Metropolitan University.

European Union, 2005. Commission decision of establishing the ecological criteria for the award of the Community eco-label to heat pump system, OJ L237, 21.9.2000, First discussion draft, November 1st.

Faltings B., 1994. Arc consistency for continuous variables. Artificial Intelligence, 65, 363376.

Feldmann, K, Meedt, O, 1995. Recycling and disassembly of electronic devices, IFIP WG5.3 International Conference on Life Cycle Modeling for Innovative Products and Processes, Berlin, Germany.

Feldmann, K., Meedt, O., Trautner, S., Scheller, H., Hoffmann, W., 1999. The "Green Design Advisor": a tool for design for environment, Journal of Electronics Manufacturing $9(1), 17-28$.

Freuder, E. (Editor), 1996. Principles and Practice of Constraint Programming-CP96. Springer Verlag LNCS 1118.

Gallastegui, I.G., 2002. The use of eco-labels: a review of the literature. European Environment, 12, 316-331. 
Gottberg, A., Morris, J., Pollard, S., Mark-Herbert, C., Cook M., 2006. Producer responsibility, waste minimisation and the WEE Directive: Case studies in eco-design from the European lighting sector. Science of the Total Environment, 359, 38-56.

Gou Q., Liang L., Huang Z., Xu C., 2008, A joint inventory model for an open-loop reverse supply chain. International Journal of Production Economics, 116, 28-42.

Grankvist, G., Biel, A., 2007. Predictors of purchase of eco-labelled food products: A panel study. Food Quality and Preference, 18, 701-708.

Grankvist, G., Dahlstrand, U., Biel, A., 2007. The impact of environmental labeling on consumer preference: negative vs. positive label. Journal of Consumer Policy, 27(2), 213230.

Hadj-Hamou, K., 2002. Contribution à la conception de produit à forte diversité et de leur chaîne logistique: une approche par contraintes, PhD thesis INPT, Toulouse, France. Halpin, T., 1999. Data modeling in ULM and ORM: a comparison. Journal of Database Management, 10(4), 4-13.

Harani, Y., 1997. Une approche multi-modèles pour la capitalisation des connaissances dans le domaine de la conception. PhD thesis INPG, Grenoble, France.

Hermenegildo, M. and the CLIP group, 1994. Some methodological issues in the design of CIAO - a generic parallel concurrent constraint system. In Principles and Practice of Constraint Programming. Springer-Verlag, LNCS 874.

Houé, R., Grabot, B., 2007a. Knowledge modeling for Eco-design, Concurrent Engineering: Research and Applications, 15(1), 7-21.

Houé, R., Grabot, B., 2007b. Structuring and modeling norms for the recyclability assessment of products during their design. International Journal of Computer Integrated Manufacturing, 20(7), 699-714.

Hsuan Hong I., Ammons J.C., Realff M.J., 2008, Decentralized decision-making and protocol design for recycled Material flows. International Journal of Production Economics, $116,325-337$ 
Hundal, M., 2000. Design For Recycling and Remanufacturing. International Design

Conference - DESIGN 2000. Dubrovnik, May 23-26.

ILOG, 1995. ILOG SOLVER: Object oriented constraint programming. User Manual.

Ishii, K., 1998. Design for Environment and Recycling: Overview of Research in the United States. CIRP 5th International Seminar on Life-cycle Engineering, September 16-18.

Jaffar, J., Michaylov, S., Stuckey, P. J., Yap, R. H. C., 1992. The CLP(R) Language and System. ACM Transactions on Programming Languages and Systems.

Janssen, P., 1990. Aide à la conception: une approche basée sur la satisfaction de contraintes. $\mathrm{PhD}$ thesis, University of Montpellier II.

Jordan, A., Wurzel, R., Zito, A., Brückner L., 2003. Consumer Responsibility-taking and National Eco-labeling Schemes in Europe. In Politics, Products and Markets: Exploring Political Consumerism. M. Micheletti, A. Follesdal and D. Stolle (Eds), Somerset, NJ. Junker, U., 2001. Quickxplain: conflict detection for arbitrary constraint propagation algorithms. Report, Ilog S.A.

Kobayashi, Y., Kobayashi, H., Hongu, A., Sanehira, K., 2005. A practical method for quantifying eco-efficiency using eco-design support tools. Journal of Industrial Ecology, 9(4), 131-144.

Kroll, E., Hanft, T.A., 1998. Quantitative Evaluation of Product Disassembly for Recycling, Research in Engineering Design (10), 1-14.

Kumar S., Putnam V., 2008, Cradle to cradle: Reverse logistics strategies and opportunities across three industry sectors. International Journal of Production Economics, 115, 305-315. Ljunberg, L.Y., 2007. Materials selection and design for development of sustainable products. Materials and Design, 28, 466-479.

Lundquist Noblet, C., Teisl, M.F., Rubin, J., 2006. Factors affecting consumer assessment of eco-labeled vehicles. Transportation Research part D, 11, 422-431.

Mackworth, A., 1977. Consistency in networks of relations. Artificial Intelligence, 8, 99-118. Mascle C., Ping Zhao H., 2008. Integrating environmental consciousness in product/process 
development based on life-cycle thinking. International Journal of Production Economics, $112,5-17$

McAloone, T.C., 1998. Industry experiences of environmentally conscious design integration: an exploratory study. $\mathrm{PhD}$ thesis Cranfield University.

Mc Donald, K., Prosser, P., 2002. A case study of constraint programming for configuration problems, http://www.dcs.st-and.ac.uk/ apes/reports/apes-45-2002.ps.gz

Michelini, R.C., Razzoli, R.P., 2004. Product-service eco-design: Knowledge-based infrastructures. Journal of Cleaner Production, 12, 415-428.

Miemczyk J., 2008. An exploration of institutional constraints on developing end-of-life product recovery capabilities. International Journal of Production Economics, 115, 272-282. Mittal, S., Falkenhainer, B., 1990. Dynamic constraint satisfaction problems. Proceedings of the Eighth National Conference on Artificial Intelligence, 25-32.

Mittal, S., Frayman, B., 1989. Towards a generic model of configuration tasks. International Joint Conference on Artificial Intelligence, vol. 2, 1395-1401.

Montanari, H., 1974. Networks of constraints: Fundamental properties and application to picture processing. Information Sciences, 7, 95-132.

Mol, A, Volkmar, L, Leifferink, D (Eds), 2000. The voluntary approach to environmental policy-making in Europe. Oxford, Oxford University Press.

Nordic Ecolabeling, 2002. Nordic Swan: Ecolabeling of Personal Computers. Criteria document, 20th April 1998 - 19th April 2002. Version 2.1.

O'Sullivan, B., 1999. Constraint-Aided Conceptual Design, PhD thesis Department of Computer Science, University College Cork.

O’Sullivan, B., Bowen, J., 1998. A constraint-based Approach to Supporting Conceptual Design. In Artificial Intelligence in Design'98, pp. 291-308, Instituto Superior Ténico, Lisbon, July.

PC 3R, 2006. PC Green Label System, http://www.pc3r.jp/pdf/g12006_e.pdf 
Pujari, D., 2006. Eco-innovation and new product development: understanding the influences on market performance. Technovation, 26, 76-85.

RAL-UZ 78, 2004. Blue Angel. Basic Criteria for Award of the Environmental Label. Workstation Computers. February Edition.

Rose, C.M., Stevels, A., Ishii, K., 2000. A new approach to end-of-life design advisor (ELDA), Proceedings of the 2000 IEEE International Symposium on Electronics and the Environment, San Francisco, USA.

Rosemann, B., Meerkamm, H., 2004. Eco design: make it happen by an environmental innovative product design. International design Conference-Design 2004, Dubrovnik, May $18-21$.

Rossi, F., 2000. Constraint Logic Programming. In Proc. ERCIM/Compulog Net workshop on constraints. Springer-Verlag, LNAI 1865.

Saucier, A., 1996. Modélisation structurelle, fonctionnelle et géométrique de produit en conception mécanique complexe. Application à la conception d'une culasse de véhicule. $\mathrm{PhD}$ thesis ENS Cachan.

Seidel, R., Shahbazpour, M., Oudshoom, M., 2006. Implementation of sustainable practices in SMEs - Case study of a New Zealand furniture manufacturer, 13th CIRP International Conference on Life Cycle Engineering, Leuven, May 31-June 2.

Simon, M., 1996. Feasibility of a common indexing system for recycling of electronic products. Technical report, Manchester Metropolitan University, Manchester, GB.

Svoboda, S., 1995. Note on Life Cycle Analysis, University of Michigan Corporate Environmental Management Program (CEMP), LCA Note (9).

Teisl, M.F., 2002. Can Eco-labels tune a market? Evidence from Dolphin-safe labeling. Journal of Environmental Economics and Management, 43, 339-359.

Teisl, M.F., Rubin, J., Noblet, C.L., 2007. Non-dirty dancing? Interaction between eco-labels and consumers. Journal of Economic Psychology, doi:10.1016/j.joep.2007.04.002. 
TCO, 2000. TCO'99 Certification requirements and test methods for environmental labeling, Ecology of display, Portable computers, System units and Keyboards. Report n5, 2nd Edition, June 20.

Thomas, A.G., Kox, F.A.J., 1996. Technical description and final evaluation of the recycling and industrial outlets, module of the DEMROP-project, in r. T.-G. 96.30, ed., Report of the Philips Centre for Manufacturing Techn., EcoDesign Group. TU, Delft, Netherlands.

Thogersen, J., 2002, Promoting green consumer behavior with eco-labels. In Thomas Dietz, Paul Stern (Eds): New tools for environmental protection: Education, information, and voluntary measures, National Academic Press, Washington DC.

Van Hemel, C.G., 1998. Eco-design empirically explored. Design for environment in Dutch small and medium sized enterprises, $\mathrm{PhD}$ thesis Delft University of Technology.

Van Hentenryck, P., Simonis, H., Dincbas, M., 1992. Constraint satisfaction using constraint logic, Artificial Intelligence 58, 113-159.

Vareilles, E., 2005. Conception et approches par propagation de contraintes: Contribution à la mise en œuvre d'un outil d'aide interactif, PhD thesis INPT, Toulouse, France.

VDI, 1993. VDI 2243 - Konstruiren recyclinggerechter technischer Produckte. V. D. Ingenieure. Berlin (Germany), Beuth Verlag GmbH.

Vezzoli, C., 1999. An overview of life cycle and information technology tools. The Journal of Sustainable Product Design, 9.

Wallace, M., Novello, S., Schimpf, J., 1997. Eclipse. A platform for constraint logic programming. Technical report, IC-Parc, Imperial College, London.

Yvars, P.A., 2001. Contribution à la représentation des connaissances en ingénierie intégrée de produits et de systèmes de production, Habilitation to direct research, INPG, Grenoble. 
Figure captions:

Table 2. Main ORM notations

Figure 9. Structural point of view

Figure 10. Recyclability point of view

Figure 11. Disassembly point of view

Figure 12. Usage point of view

Figure 13. Identification of plastic components

Figure 14. The constraints network of the study

Figure 15. Drawing of the CPU (Kroll and Hanft, 1998)

Figure 16. Simplified bill of materials of the CPU (Kroll and Hanft, 1998) 


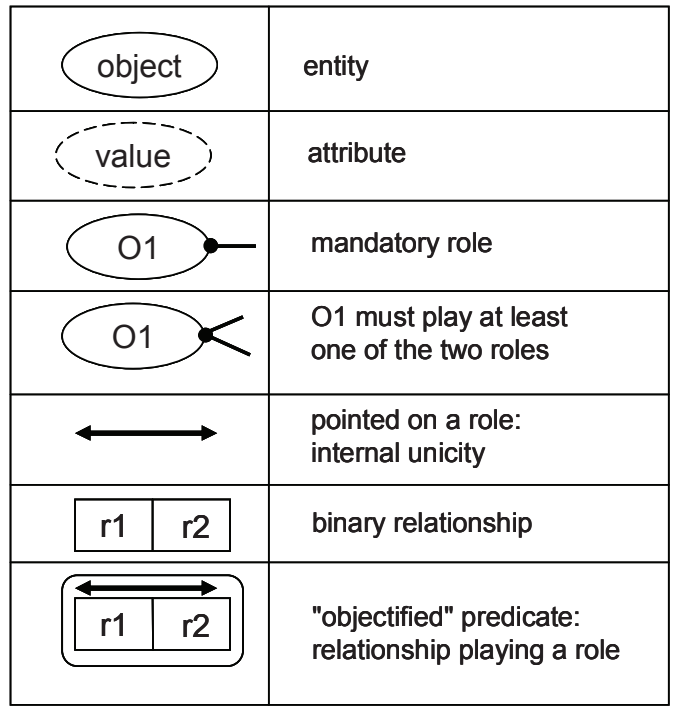

Table 1 


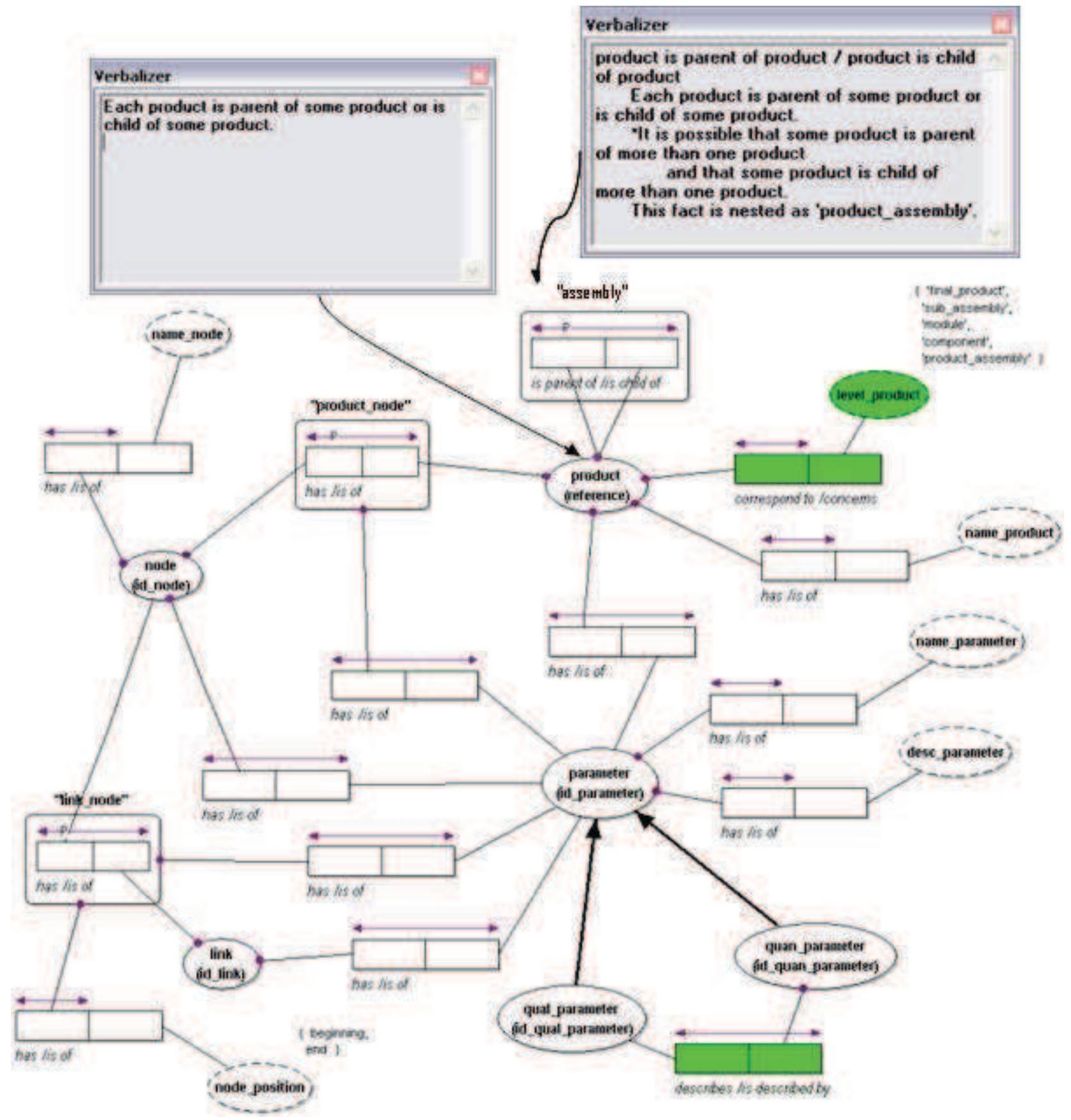

Figure 1 


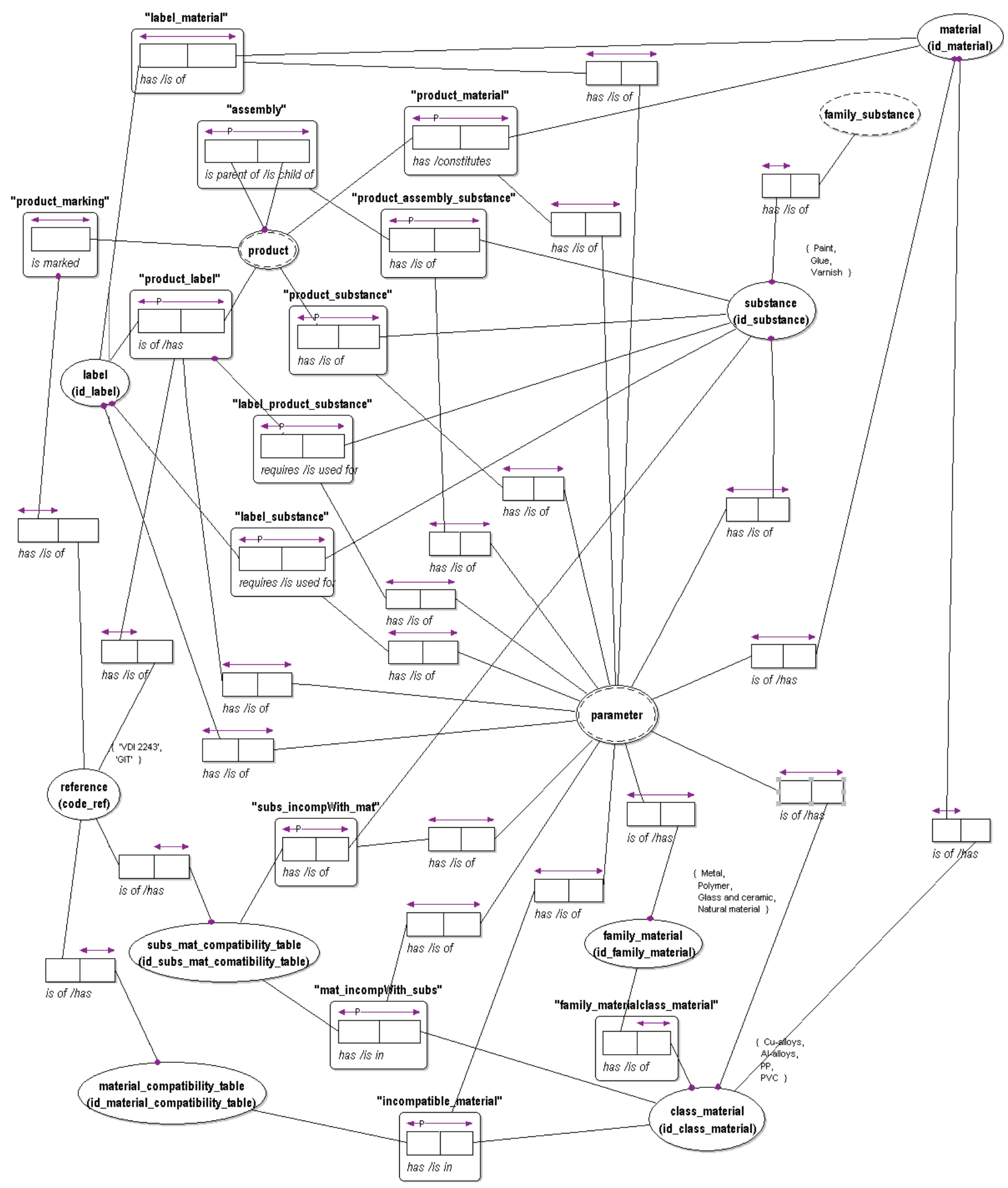

Figure 2 


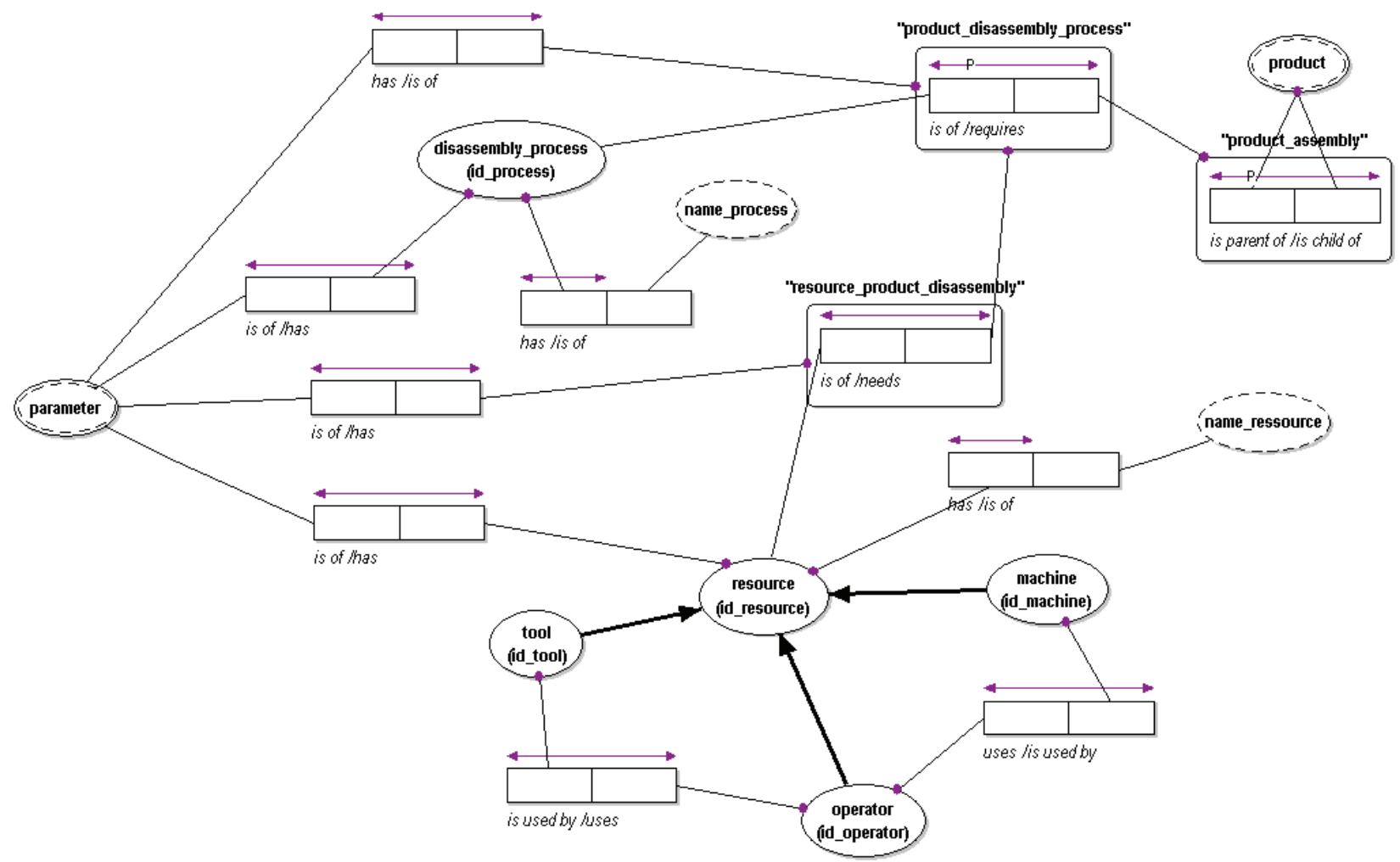

Figure 3 


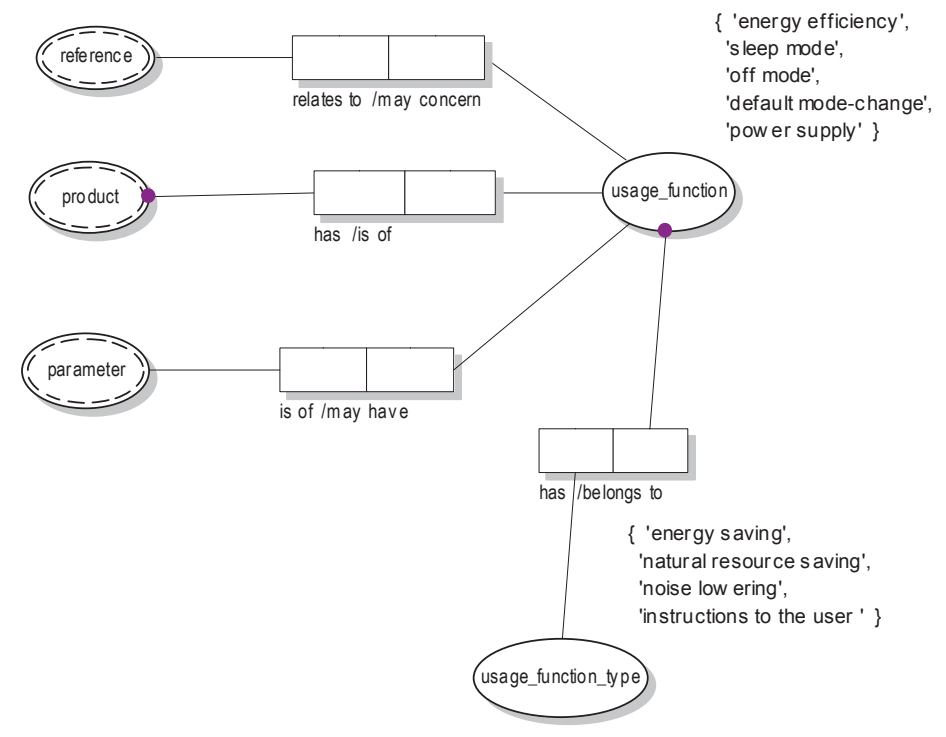

Figure 4 


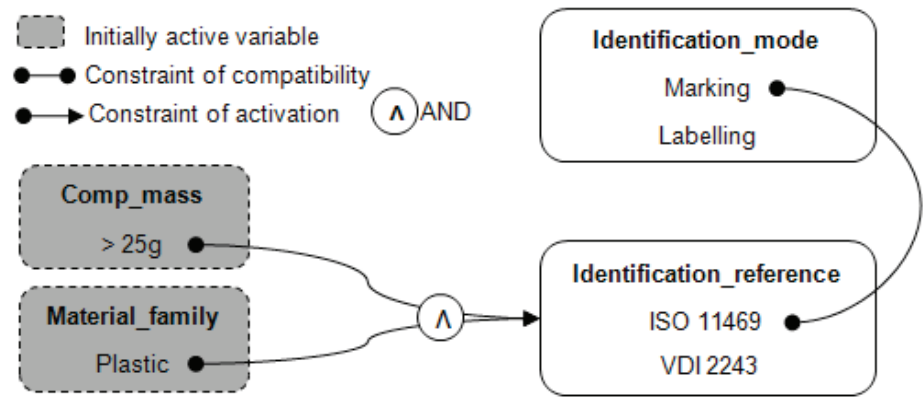

Figure 5 


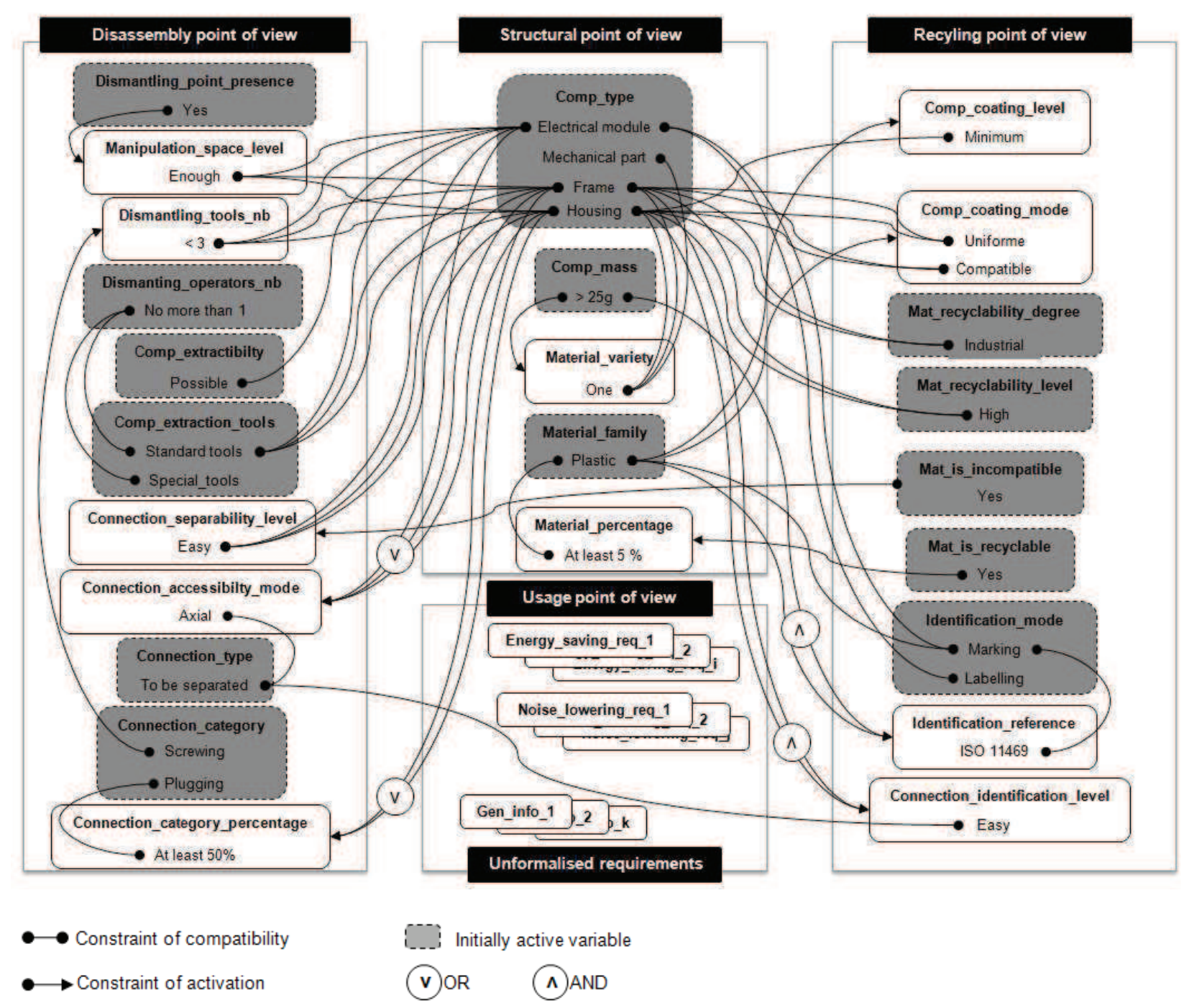

Figure 6 


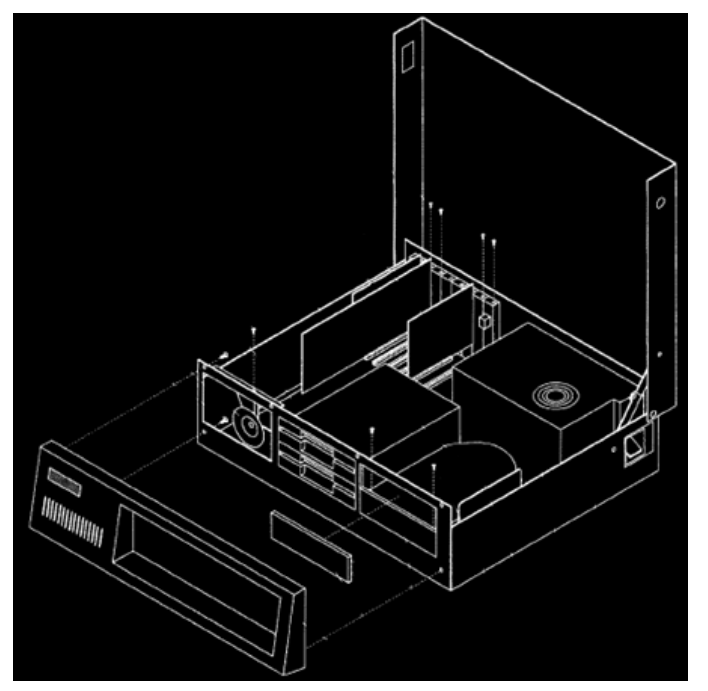

Figure 7 


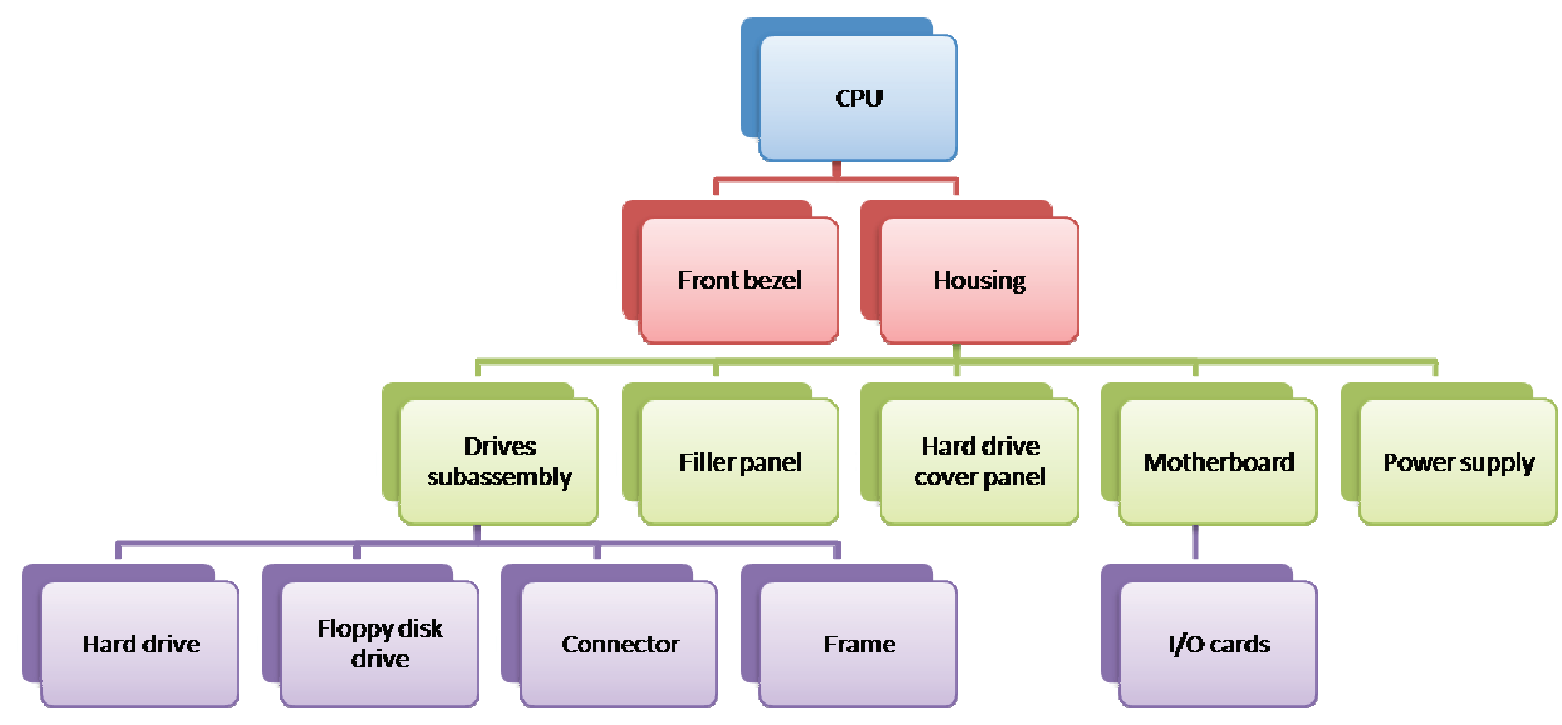

Figure 8 